\title{
IMPORTAÇÕES BRASILEIRAS DE LEITE: IMPACTOS MICRO E MACROECONÔMICOS
}

\author{
Dione Fraga dos Santos ${ }^{\S}$ \\ Geraldo Sant'Ana de Camargo Barros ${ }^{\not}$
}

\section{Resumo}

Nos anos 1990 houve mudanças significativas no setor agroindustrial do leite no Brasil. Dentre elas destacam-se: a desregulamentação do rigoroso controle estatal após 46 anos (1945-1991); o lançamento de novos produtos; a entrada de multinacionais; a criação do Mercosul e a abertura comercial generalizada. O comércio mundial de lácteos tem a participação de poucos países, sendo os principais importadores e exportadores os países membros da OCDE. Países como o Brasil e a Índia possuem parcelas pouco expressivas do volume de comércio. O objetivo geral da pesquisa é analisar os fatores que têm influenciado as importações de lácteos pelo Brasil no período de 1991 a 2003. A metodologia empregada para medir os impactos sobre as importações de leite de variáveis micro e macroeconômicas foi a de séries temporais. Incorporou-se uma análise gráfica a partir do diagrama back to back. Utilizou-se a equação de excesso de demanda para definir a demanda por importação de leite.

Palavras-chave: séries temporais, diagrama “back to back”, taxa de câmbio, importação, leite.

\begin{abstract}
During the decade of the 1990's several significant changes took place in the milk agroindustry sector in Brazil: the sector was deregulated after 46 years of state control; new milk products were created; the market share of multinational enterprises increased; the Mercosul was created; and the economy was opened through tariff reduction and deregulations. Only a few countries participate in the world milk trade. Major importers and exporters are members of OECD. The trade share of countries like Brazil and India in rather small. The general objective of this study is to analyze the micro and macro factors that influenced the imports of milk by Brazil during the period from 1991 to 2003. The milk imports market is analyzed through "back to back" graphic system such that Brazil imports demand faces the world export supply.
\end{abstract}

Key words: time series, back to back diagram, foreign exchange, import, milk.

JEL classification: C32, F11, F31.

$\S \quad$ Doutora em Economia Aplicada (Esalq-USP), Professora Adjunta I da FEA-UFJF. E-mail: dione.fraga@terra.com.br. Endereço para contato: Campus UFJF - Faculdade de Economia e Administração - FEA - ANE - CEP 36036-330 - Juiz de Fora - MG.

a Professor Titular e coordenador do Centro de Estudos Avançados em Economia Aplicada (CEPEA), Esalq-USP. E-mail: gscbarro@esalq.usp.br.

Recebido em dezembro de 2004. Aprovado em abril de 2006. 


\section{INTRODUÇÃO}

O sistema agroindustrial do leite no País passou por importantes alterações desde o início da década de 1990. O segmento de leite fluido experimentou a desregulamentação do setor após 46 anos de controle governamental no estabelecimento de preço do leite tipo C. A abertura econômica e a formação do Mercosul levaram as empresas à competição com empresas de grande porte e a enfrentar os preços praticados muitas vezes distorcidos no resto do mundo. A reação da cadeia produtiva parece ter sido positiva: houve reorganização intensa na pecuária leiteira com aumento de competitividade para enfrentar a concorrência externa. Concomitantemente, houve lançamentos de novos produtos e derivados, a abertura econômica do País e a formação do Mercosul. No Brasil, houve concentração das empresas de laticínios e a entrada de empresas multinacionais no mercado. Em paralelo, houve um aumento expressivo da participação relativa do leite UHT no mercado nacional de leite fluido.

No mesmo período, aumentou a importação brasileira de lácteos oriundos da Argentina, Uruguai, União Européia e Nova Zelândia, países que possuem preços abaixo da média dos praticados no mercado internacional, provavelmente influenciados por medidas de dumping. A Confederação Nacional da Agricultura (CNA) iniciou o processo de investigação de dumping no período de julho de 1998 a junho de 1999. Esta possibilidade de importações, segundo Barros et al. (2001), passou a estabelecer um limite superior de preços no segmento de leite brasileiro.

O comércio mundial de lácteos tem a participação de poucos países, sendo os principais importadores e exportadores os países membros da Organização para Cooperação e Desenvolvimento Econômico $\left(\mathrm{OCDE}^{1}\right)$. Países em desenvolvimento, como Índia e Brasil, possuem parcelas pouco expressivas do volume de comércio, apesar de terem sido o segundo e sexto produtores mundiais, respectivamente, em 2002.

De que forma e em que grau a inserção internacional influenciou o mercado interno? Em que grau possíveis influências negativas foram superadas pelo próprio setor ou por medidas adotadas pelo governo brasileiro? Estas são as questões tratadas neste trabalho.

Com o objetivo geral de respondê-las, primeiramente enfoca-se o comércio internacional de leite no mundo, destacando seus maiores exportadores e importadores bem como as medidas implementadas pelo Brasil para impedir a prática de políticas comerciais que prejudicam o produtor nacional. Em segundo lugar, faz-se a análise com base num modelo teórico, e a seguir estima-se o comportamento das quantidades importadas de lácteos como função de preços de importação, taxa de câmbio real, renda per capita, preço doméstico de leite, estabilização monetária e política anti-dumping.

A análise da demanda de importação desenvolvida neste trabalho incorpora o efeito de variáveis macroeconômicas importantes, como, por exemplo, taxa de câmbio e renda nacional, sendo a estimação feita por meio de procedimentos econométricos pertinentes, considerando as questões de estacionariedade e co-integração. Ressalta-se que a contribuição do trabalho é a investigação a respeito do método adequado de estimação da função de demanda de importação de leite para o Brasil e referendar a tese de Balassa ${ }^{2}$ (1967), de que os impactos das distorções de mercado aparecem incorporados nos preços observados.

1 Alemanha, Dinamarca, França, Itália, Noruega, Suíça, Canadá, Austrália, Áustria, Finlândia, Grã-Bretanha, Holanda, Portugal, Turquia, Espanha, Nova Zelândia, Bélgica, Irlanda, Grécia, Islândia, Luxemburgo, Suécia, Estados Unidos, Japão, México, República Tcheca, Eslováquia, Polônia e Coréia.

2 Balassa, B. Trade liberalization among industrial countries: objectives and alternatives. New York: McGraw Hill, 1967. 251p. 
O presente artigo está dividido em quatro seções sem contar com esta introdução. A primeira refere-se à revisão de literatura; a segunda, à metodologia; a terceira, aos resultados; e a quarta à conclusão.

\section{REVISÃO DE LITERATURA}

\subsection{Comércio internacional e nacional de leite fluido}

Dados da FAO (2003) apontaram, para 2002, os Estados Unidos como maior produtor, com cerca de $15 \%$ da produção mundial. A Federação Russa detinha cerca de $7 \%$ da produção mundial. No ano de 2002, o Brasil produziu 23 milhões de toneladas métricas de leite, representando 4,7\% da produção mundial, quantidade que o colocou como o sexto maior produtor do mundo. A produção brasileira vem crescendo a uma taxa superior à da produção mundial: em 1995, a participação brasileira foi de 3,6\% e o País apresentou-se como o sétimo maior produtor.

A produção mundial de leite tendeu à elevação em países em desenvolvimento, como China e Índia. (FAO, 2004). A produção nos países em desenvolvimento cresceu, em média, 4,0\% na década de 1990 e permaneceu estagnada nos países desenvolvidos.

Em 1995, os países desenvolvidos tiveram um consumo per capita $70 \%$ superior à média de consumo dos países em desenvolvimento. Em 2000, a cifra foi para 100\%. Para 2003, a USDA (2004) estimou-o em $80 \%$.

As Tabelas 1 e 2 mostram que os vinte maiores países exportadores de leite detinham cerca de $89 \%$ das exportações mundiais do produto no ano de 2001. Observou-se ainda que existiam diferenças das participações nos valores exportados e nas quantidades, refletindo desigualdades na composição das exportações. Por exemplo, a França, que detinha 13,06\% do valor das exportações mundiais de leite, e apenas $12,75 \%$ das quantidades, evidenciava que seus produtos exportados tinham preços mundiais mais elevados do que a média. Em contrapartida, a Nova Zelândia detinha $13 \%$ das quantidades exportadas de leite e 10,49\% do valor das exportações do produto, indicando, grosso modo, que suas exportações de leite ocorreram com preços inferiores à média.

Os 20 maiores importadores adquiriram $75 \%$ do total das importações mundiais no produto (FAO, 2003), sendo que os seis maiores importadores mundiais foram os países membros da União Européia (UE), que se destacaram tanto como grandes exportadores de lácteos como grandes importadores, o que caracteriza o elevado grau de comércio intra-indústria existente nesse segmento. 
Tabela 1 - Vinte maiores exportadores de leite, valor em mil dólares americanos, quantidade em toneladas e participação (\%), 2001

\begin{tabular}{|c|c|c|c|c|c|}
\hline \multirow{2}{*}{ Posições } & \multirow{2}{*}{ Países } & \multirow{2}{*}{$\begin{array}{c}\text { Valor } \\
\text { US\$1.000 }\end{array}$} & \multirow{2}{*}{$\begin{array}{c}\text { Quantidade } \\
t\end{array}$} & \multicolumn{2}{|c|}{ Participações } \\
\hline & & & & Valor (\%) & Qtde (\%) \\
\hline & Mundo & 27.629 .224 & 71.888 .620 & 100,00 & 100,00 \\
\hline & Vinte maiores & 24.710 .717 & 63.865 .630 & 89,44 & 88,84 \\
\hline 1 & Alemanha & 4.117.629 & 10.511 .542 & 14,90 & 14,62 \\
\hline 2 & França & 3.608 .166 & 9.166 .400 & 13,06 & 12,75 \\
\hline 3 & Holanda & 3.008 .513 & 6.546 .840 & 10,89 & 9,11 \\
\hline 4 & Nova Zelândia & 2.897 .098 & 9.343 .692 & 10,49 & 13,00 \\
\hline 5 & Bélgica & 1.755 .853 & 4.250 .514 & 6,36 & 5,91 \\
\hline 6 & Austrália & 1.592 .518 & 4.933 .888 & 5,76 & 6,86 \\
\hline 7 & Dinamarca & 1.276 .547 & 2.128 .986 & 4,62 & 2,96 \\
\hline 8 & Irlanda & 1.114.076 & 2.673 .918 & 4,03 & 3,72 \\
\hline 9 & Itália & 933.475 & 1.130 .587 & 3,38 & 1,57 \\
\hline 10 & Reino Unido & 796.740 & 2.152 .778 & 2,88 & 2,99 \\
\hline 11 & Estados Unidos & 638.173 & 2.762 .723 & 2,31 & 3,84 \\
\hline 12 & Espanha & 543.475 & 1.088 .267 & 1,97 & 1,51 \\
\hline 13 & Áustria & 501.125 & 1.169 .497 & 1,81 & 1,63 \\
\hline 14 & Polônia & 421.596 & 1.391 .532 & 1,53 & 1,94 \\
\hline 15 & Suíça & 319.956 & 433.990 & 1,16 & 0,60 \\
\hline 16 & Argentina & 282.510 & 952.989 & 1,02 & 1,33 \\
\hline 17 & Ucrânia & 274.502 & 1.158 .159 & 0,99 & 1,61 \\
\hline 18 & Canadá & 270.436 & 868.411 & 0,98 & 1,21 \\
\hline 19 & República Tcheca & 202.544 & 814.633 & 0,73 & 1,13 \\
\hline 20 & Suécia & 155.785 & 386.284 & 0,56 & 0,54 \\
\hline
\end{tabular}

Fonte: FAO (2003). 
Tabela 2 - Vinte maiores importadores leite, valor em mil dólares americanos, quantidade em toneladas e participação (\%), 2001

\begin{tabular}{|c|c|c|c|c|c|}
\hline \multirow{2}{*}{ Posição } & \multirow{2}{*}{ Países } & \multirow{2}{*}{$\begin{array}{c}\text { Valor } \\
\text { US\$1.000 }\end{array}$} & \multirow{2}{*}{$\begin{array}{c}\text { Quantidade } \\
t\end{array}$} & \multicolumn{2}{|c|}{ Participações } \\
\hline & & & & Valor (\%) & Qtde (\%) \\
\hline & Mundo & 26.909 .490 & 67.120 .530 & 100,00 & 100,00 \\
\hline & Vinte maiores & 20.217 .477 & 49.528 .475 & 75,13 & 73,79 \\
\hline 1 & Alemanha & 2.659 .059 & 4.893 .537 & 9,88 & 7,29 \\
\hline 2 & Itália & 2.412 .626 & 5.202 .858 & 8,97 & 7,75 \\
\hline 3 & França & 1.884 .775 & 4.449 .944 & 7,00 & 6,63 \\
\hline 4 & Bélgica & 1.853 .034 & 4.118 .281 & 6,89 & 6,14 \\
\hline 5 & Reino Unido & 1.621 .194 & 2.761 .465 & 6,02 & 4,11 \\
\hline 6 & Holanda & 1.544 .434 & 5.957 .434 & 5,74 & 8,88 \\
\hline 7 & Estados Unidos & 1.378 .054 & 1.873 .417 & 5,12 & 2,79 \\
\hline 8 & Espanha & 863.932 & 1.914 .453 & 3,21 & 2,85 \\
\hline 9 & México & 858.669 & 2.779 .261 & 3,19 & 4,14 \\
\hline 10 & China & 830.015 & 2.812 .550 & 3,08 & 4,19 \\
\hline 11 & Japão & 784.829 & 1.683 .286 & 2,92 & 2,51 \\
\hline 12 & Arábia Saudita & 546.334 & 1.055 .254 & 2,03 & 1,57 \\
\hline 13 & Argélia & 530.430 & 1.808 .415 & 1,97 & 2,69 \\
\hline 14 & Grécia & 446.220 & 1.235 .729 & 1,66 & 1,84 \\
\hline 15 & Filipinas & 436.459 & 1.596 .088 & 1,62 & 2,38 \\
\hline 16 & Federação Russa & 389.626 & 1.599 .123 & 1,45 & 2,38 \\
\hline 17 & Indonésia & 326.326 & 1.106 .029 & 1,21 & 1,65 \\
\hline 18 & Canadá & 292.183 & 733.786 & 1,09 & 1,09 \\
\hline 19 & Tailândia & 290.922 & 1.126 .882 & 1,08 & 1,68 \\
\hline 20 & Cingapura & 268.356 & 820.683 & 1,00 & 1,22 \\
\hline
\end{tabular}

Fonte: FAO (2003).

$\mathrm{Na}$ Tabela 3 observam-se os dados sobre as exportações e importações líquidas para o ano de 2001. O maior exportador líquido mundial foi a Nova Zelândia, seguida da França e da Holanda. Já o maior importador líquido mundial foi a Itália, seguida da Bélgica. 
Tabela 3 - Dez maiores exportadores e importadores líquidos de leite, 2001

\begin{tabular}{llc|clc}
\hline Posição & Países & $\begin{array}{c}\text { Exportações } \\
\text { US\$ } 1.000\end{array}$ & Posição & Países & $\begin{array}{c}\text { Importações } \\
\text { US\$ } 1.000\end{array}$ \\
\hline 1 & Nova Zelândia & 2.880 .411 & 1 & Itália & 1.479 .151 \\
2 & França & 1.723 .391 & 2 & Bélgica & 824.454 \\
3 & Holanda & 1.464 .079 & 3 & Reino Unido & 824.454 \\
4 & Alemanha & 1.458 .570 & 4 & Estados Unidos & 739.881 \\
5 & Austrália & 1.424 .268 & 5 & China & 647.416 \\
6 & Dinamarca & 1.054 .071 & 6 & Espanha & 320.457 \\
7 & Irlanda & 897.768 & 7 & Federação Russa & 266.821 \\
8 & Polônia & 300.934 & 8 & Brasil & 157.513 \\
9 & Ucrânia & 257.079 & 9 & Suécia & 24.495 \\
10 & Argentina & 255.024 & 10 & Canadá & 21.747 \\
\hline
\end{tabular}

Fonte: FAO (2003).

\subsection{Tarifas e subsídios de importação}

É importante enfatizar que o comércio de produtos lácteos foi submetido, de forma geral, a pesadas barreiras tarifárias. A Tabela 4 apresenta as tarifas consolidadas na Organização Mundial de Comércio (OMC) em diversas regiões do mundo. A tarifa ad valorem média do segmento foi de $86 \%$, segunda maior tarifa média do setor agrícola, superada apenas pelo fumo. Com relação às regiões, observam-se valores em torno de $85 \%$ na América do Norte e na União Européia.

Tabela 4 - Tarifas consolidadas do segmento lácteo

\begin{tabular}{|c|c|}
\hline Regiões & Tarifa ad valorem média \\
\hline Mundo & 86 \\
\hline Sul da África & 39 \\
\hline Ásia - Pacífico & 73 \\
\hline Sul da Ásia & 104 \\
\hline África - subsaara & 75 \\
\hline África do Norte & 74 \\
\hline Oriente Médio & 65 \\
\hline Europa Oriental & 85 \\
\hline Europa Ocidental $^{1}$ & 230 \\
\hline União Européia & 87 \\
\hline América do Sul & 43 \\
\hline América Central & 68 \\
\hline Ilhas do Caribe & 87 \\
\hline América do Norte & 85 \\
\hline
\end{tabular}

Fonte: Brandão e Leite (2001).

1 Exceto UE. 
Para Brandão e Leite (2001), as distorções nos preços internacionais causadas pelas políticas comerciais permaneceram elevadas no setor agrícola. A Rodada Uruguai do Acordo Geral sobre Tarifas e Comércio (GATT) determinou que os países convertessem barreiras não-tarifárias (cotas, tarifas variáveis) nos equivalentes tarifários, processo que ficou conhecido por "tarificação". Porém, as reduções efetivas de tarifa foram pouco significativas.

Thorstensen (1999) afirmou, no entanto, que o acordo obtido na Rodada Uruguai foi importante, pois reduziu os subsídios às exportações e os apoios domésticos aos produtores. A redução das tarifas significou uma diminuição de $37 \%$, em média, para todos os produtos, com as reduções variando de $48 \%$ para flores e plantas até $26 \%$ para lácteos.

O subsídio utilizado para estimular as exportações, embora proibido pela OMC, é praticado no comércio de produtos agrícolas nos países desenvolvidos, como a União Européia. Martins (2002), utilizando o conceito de $\mathrm{SEP}^{3}$ (Subsídio de Equivalência ao Produtor), indica o elevado grau de subsídio ao leite aplicado pelos países da OCDE, referendando os resultados de Brandão e Leite (2001).

Este artigo não pretende estimar o efeito das tarifas e subsídios sobre a importação de leite brasileira, porém destacou-os como dois instrumentos de política comercial que podem ter afetado os preços internacionais do produto. Sabe-se que existiu durante todo o período de estudo proteção à produção leiteira nos países dos quais o Brasil importou leite. Além de não haver uma série de dados sobre subsídios e tarifas que se adequassem às demais séries mensais, ressalta-se que o preço de importação do leite, presente no modelo econométrico, incluirá implicitamente o efeito das tarifas e dos subsídios, conforme Balassa (1967).

\subsection{Taxa de câmbio e a agricultura}

Schuh (1974) enfatizou a relevância da taxa de câmbio no estudo dos problemas agrícolas norte-americanos. Considerou a agricultura no agregado, e também que a mesma possuía potencial para ser um setor exportador. Admitindo-se que a moeda (dólar) do país fosse supervalorizada, ocorreria queda na demanda externa pelo produto do país em decorrência do encarecimento do produto em outras moedas, coeteris paribus. Ao menor preço em dólar, a quantidade interna demandada aumentaria e a quantidade ofertada declinaria e, logo, as exportações se reduziriam.

Greenshields (1974) pretendeu responder quais variáveis são significativas para o comércio entre os dois países. Chegou à conclusão que a taxa de câmbio não foi significativa para determinar o nível de comércio agrícola entre Estados Unidos e Japão na década de 1960. Collins et al. (1980) argumentaram que o modelo apropriado para os efeitos da taxa de câmbio requer o reconhecimento de que em muitos países existem políticas agrícolas que isolam o mercado interno dos mercados internacionais e concluíram que, de fato, as políticas que isolam o mercado externo do mercado doméstico diminuem os efeitos das mudanças da taxa de câmbio.

Orden (1986) utilizou o método VAR (vetor auto-regressivo) para analisar os efeitos da oferta monetária, da taxa de câmbio e da taxa de juros sobre as exportações agrícolas e sobre os preços recebidos pelos produtores norte-americanos. $\mathrm{O}$ autor concluiu que estas variáveis apresentam papel significativo na determinação das exportações agrícolas e dos preços agrícolas. A política monetária foi forte o suficiente para determinar os preços relativos na agricultura quando os estoques monetários estão grandes. A taxa de câmbio e a taxa de juros tinham um maior efeito no valor total das exportações se comparado à oferta monetária.

3 A OCDE, desde 1987, mede o SEP, que em sua forma algébrica é dado por: $\% S E P=\frac{S E P}{Q \cdot P_{p}+P} \cdot 100$, em que $S E P$ por países ou por mercadoria em termos monetários; $P P=$ pagamento aos produtores; $Q . P_{p}=$ valor da produção a preços de mercado e $Q . P_{b}$ valor da produção com o apoio governamental. (Portugal, 2004). 


\section{MÉTODO TEÓRICO E EMPÍRICO}

\subsection{Referencial teórico}

\section{O Diagrama "back to back"}

O modelo econômico admite uma sustentação gráfica por meio do diagrama "back to back" analisado por Barros (2003). Na Figura 1, tem-se o diagrama em que à direita do eixo vertical estão as curvas normais de oferta e da demanda referente a certo produto para o país $a$. À esquerda, as curvas do país $b$ são invertidas, pois as quantidades para essa região são obtidas da direita para a esquerda a partir do ponto de origem $(\mathrm{O})$.

\section{Figura 1 - Diagrama "back to back"}

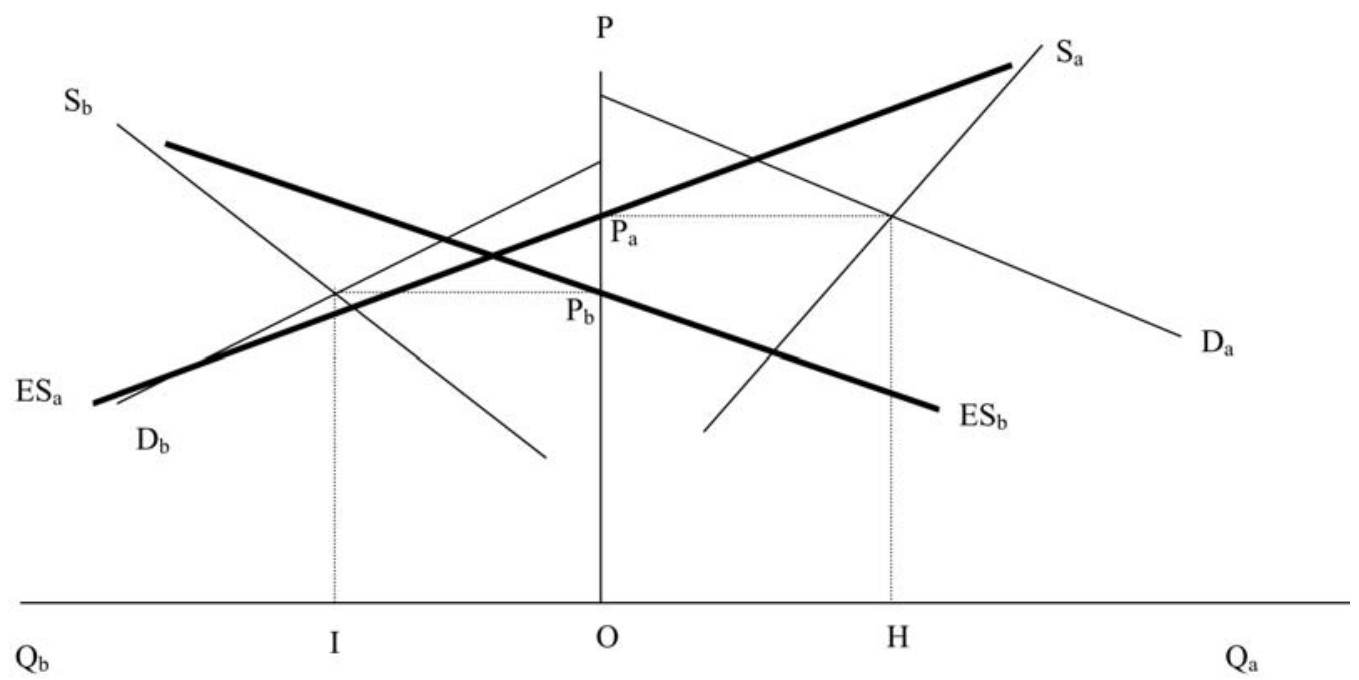

Fonte: Barros (2003).

As curvas de excesso de oferta para os países são traçadas com o intuito de mostrar os diferentes níveis de preços e os respectivos montantes pelos quais a oferta excede a demanda. Obtém-se o excesso de oferta $\mathrm{ES}_{\mathrm{a}}$ e $\mathrm{ES}_{\mathrm{b}}$, tomando-se para cada nível de preço a diferença horizontal entre a curva de oferta e a curva de demanda dos países. $\mathrm{P}_{\mathrm{a}}$ e $\mathrm{P}_{\mathrm{b}}$ são os preços em cada país na ausência de comércio entre eles.

Para atender aos objetivos do trabalho foi necessário efetuar algumas modificações no diagrama "back to back" apresentadas na Figura 1. Na Figura 2, o país a representa o Brasil, o país $b$, o Resto do Mundo, e a mercadoria em questão é o leite. O excesso de oferta no Brasil (ES $)$ passa a excesso de demanda, a preços de equilíbrio no mercado interno, $\mathrm{P}_{\mathrm{a}}^{0}$. O preço internacional é, em moeda nacional, $\mathrm{P}_{\mathrm{RM}}^{0}$. Assim, tem-se que $\mathrm{ES}_{\mathrm{a}}$ é a curva de importação do produto para preços inferiores a $\mathrm{P}_{\mathrm{a}}^{0}$. A curva de excesso de oferta do Resto do Mundo é perfeitamente elástica, que representa a oferta de importação do produto, considerando o Brasil um pequeno importador. 
Figura 2 - Diagrama back to back com custo de transferência

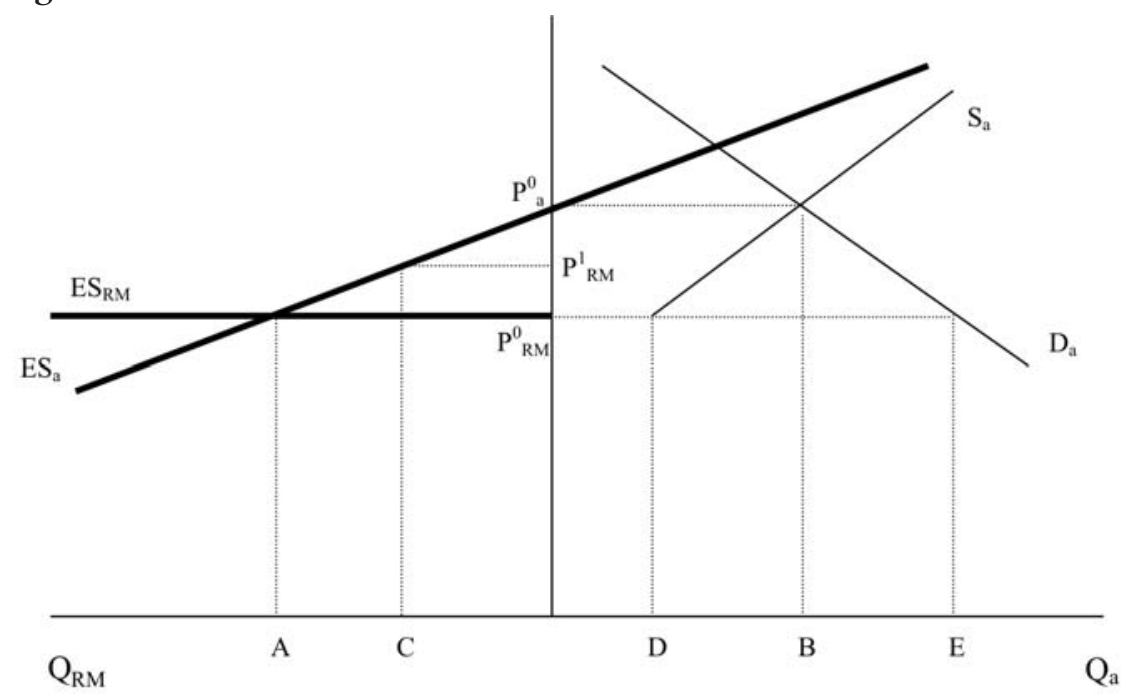

Fonte: Elaboração dos autores.

Supondo inicialmente que o custo de transferência (CT) - que inclui transporte, tarifa e outros - seja maior que a diferença de preços $\left(\mathrm{P}_{\mathrm{a}}^{0}-\mathrm{P}_{\mathrm{RM}}^{0}\right)$, então o Brasil passaria da condição de importador para a de exportador. Para o estabelecimento do comércio, considera-se inicialmente que o custo de transferência seja nulo $(\mathrm{CT}=0)$. O preço nas duas regiões se estabelece quando $\mathrm{ES}=$ $\mathrm{ES}_{\mathrm{RM}}$. O P ${ }_{\mathrm{RM}}^{0}$ é o preço no qual o leite será comercializado do Resto do Mundo para o Brasil. Em $\mathrm{P}_{\mathrm{RM}}^{0}$, haverá demanda por importação no Brasil pela quantidade DE, o mesmo montante que OA. Quando o custo de transferência CT $=k$, então o preço no Brasil passará a ser $\mathrm{P}_{\mathrm{RM}}^{1}=\left(\mathrm{P}_{\mathrm{RM}}^{0}+\mathrm{k}\right)$, sendo que a quantidade importada pelo Brasil iguala-se a OC (Figura 2).

\section{Figura 3 - Diagrama back to back com alteração da demanda}

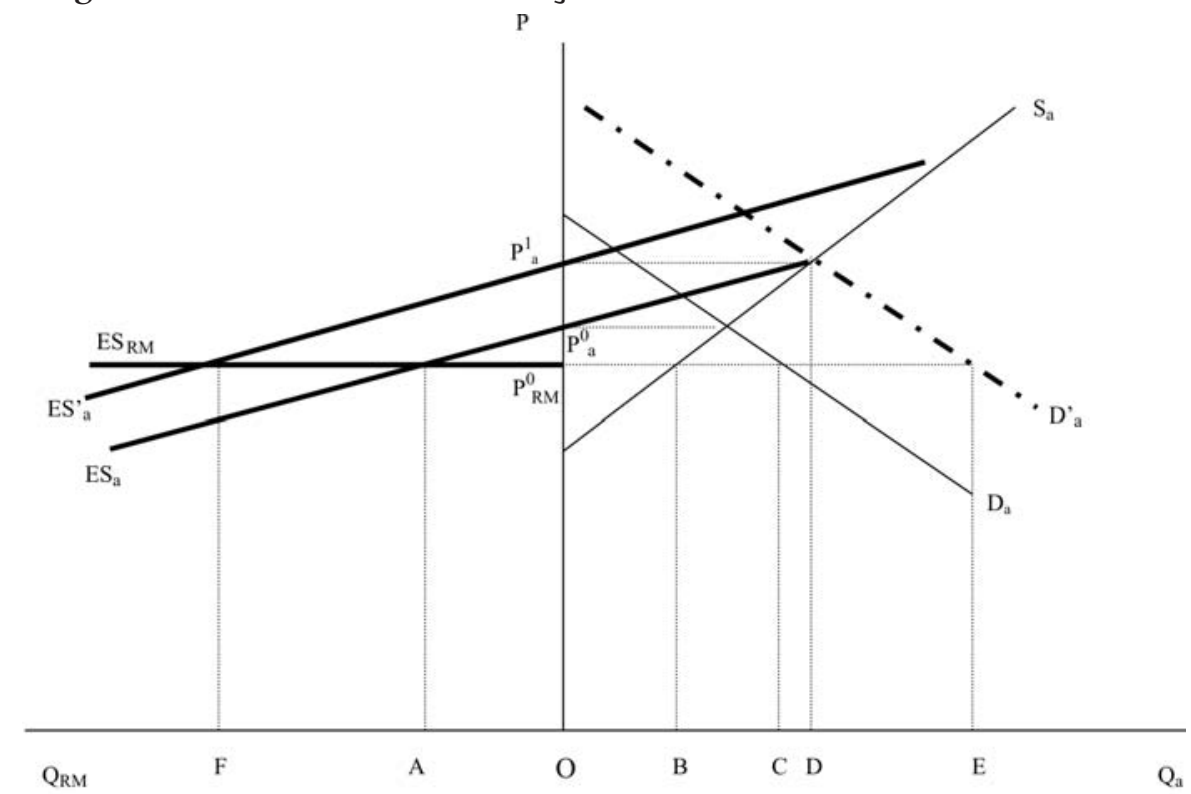

Fonte: Elaboração dos autores. 
Se ocorrer um aumento de renda interna no Brasil, por exemplo, isto possibilitará um acréscimo na demanda, que se desloca de $\mathrm{D}_{\mathrm{a}}$ para $\mathrm{D}_{\mathrm{a}}$ na Figura 3. Com a nova curva de demanda por leite haveria aumento do preço interno de $\mathrm{P}_{a}^{0}$ para $\mathrm{P}_{\mathrm{a}}^{1}$ se não houvesse importação $\left(\mathrm{CT}>\mathrm{P}^{1}{ }_{\mathrm{a}}-\mathrm{P}_{\mathrm{RM}}^{0}\right) \mathrm{A}$ curva de importação do Brasil desloca-se de $\mathrm{ES}_{\mathrm{a}}$ para $\mathrm{ES}_{\mathrm{a}}$. Se CT = 0, a produção nacional $(\mathrm{OB})$ não se altera e o consumo nacional crescerá de $\mathrm{OD}$ para $\mathrm{OE}$. $\mathrm{O}$ país importará a parcela $\mathrm{BE}=\mathrm{OF}$ oferecida ao preço $\mathrm{P}_{\mathrm{RM}}^{0}$ pelo Resto do Mundo. E o montante a mais que se espera importar DE é igual à AF.

Supondo agora, por exemplo, que haja um aumento na produção de leite brasileira que aumente a oferta de leite no mercado interno, a curva $S_{a}$ se deslocará paralelamente até $S_{a}$, reduzindo o preço interno de $\mathrm{P}_{\text {a }}^{0}$ para $\mathrm{P}_{\text {a }}^{1}$ na ausência de importação. Porém, a quantidade importada cairá de $\mathrm{BF}$ para $\mathrm{CF}=\mathrm{OE}$, supondo $\mathrm{CT}=0$. $\mathrm{O}$ produtor nacional que antes ofertava $\mathrm{OB}$ ao preço internacional ofertará OC (Figura 4).

Figura 4 - Diagrama back to back com alteração de oferta

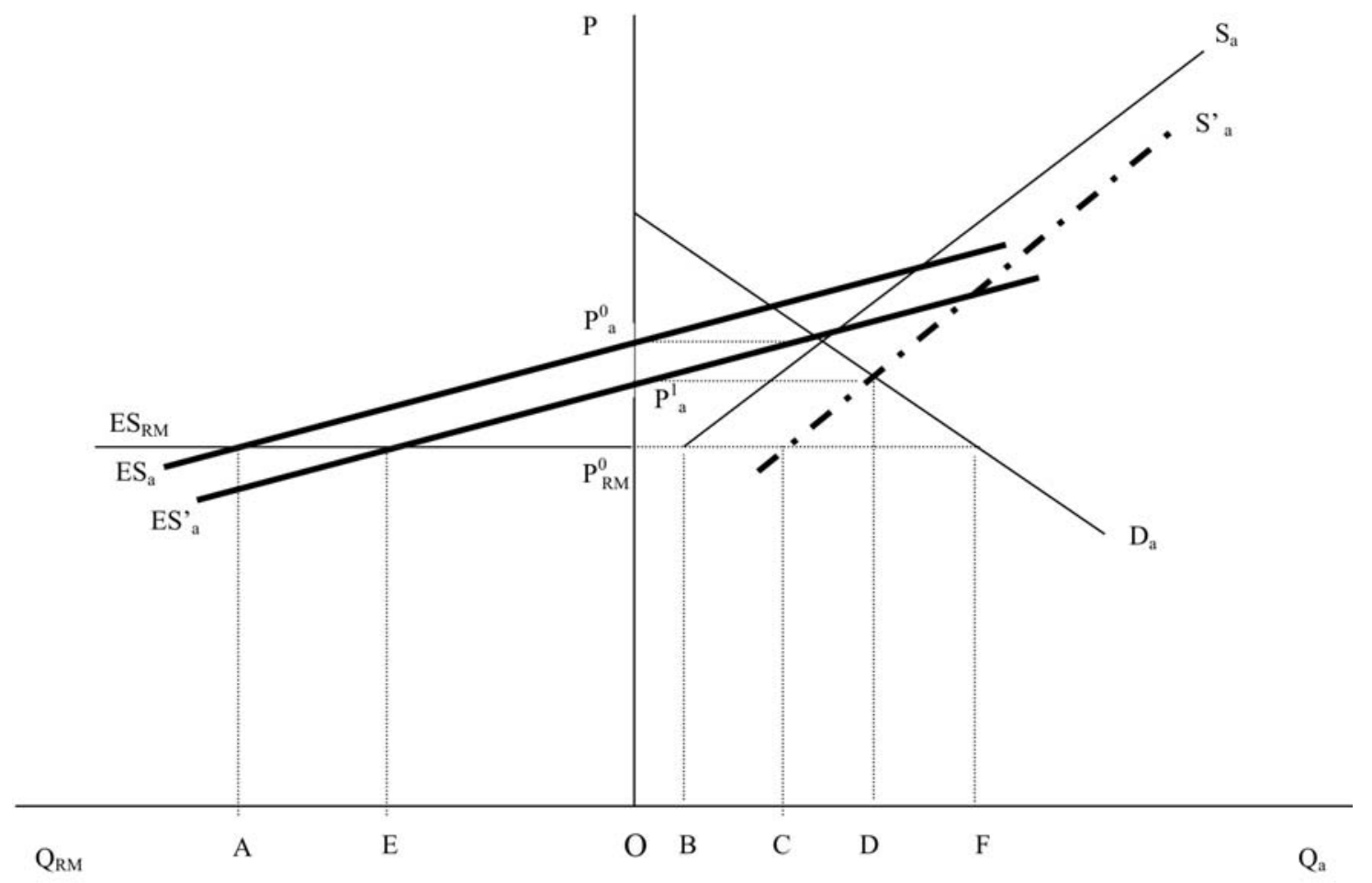

Fonte: Elaboração dos autores.

Se ocorrer uma diminuição dos subsídios diretos no Resto do Mundo, fazendo com que os preços internacionais aumentem $\left(\mathrm{P}_{\text {RM }}^{\mathrm{O}}\right.$ para $\left.\mathrm{P}_{\mathrm{RM}}^{1}\right)$, conforme apresentado na Figura 5, pelo deslocamento de $\mathrm{ES}_{\mathrm{RM}}$ para $\mathrm{ES}_{\mathrm{RM}}$, o Brasil que importava $\mathrm{BC}=\mathrm{AO}$ passa a exportar $\mathrm{OD}(=\mathrm{EF})$. 
Figura 5 - Diagrama back to back com diminuição do subsídio

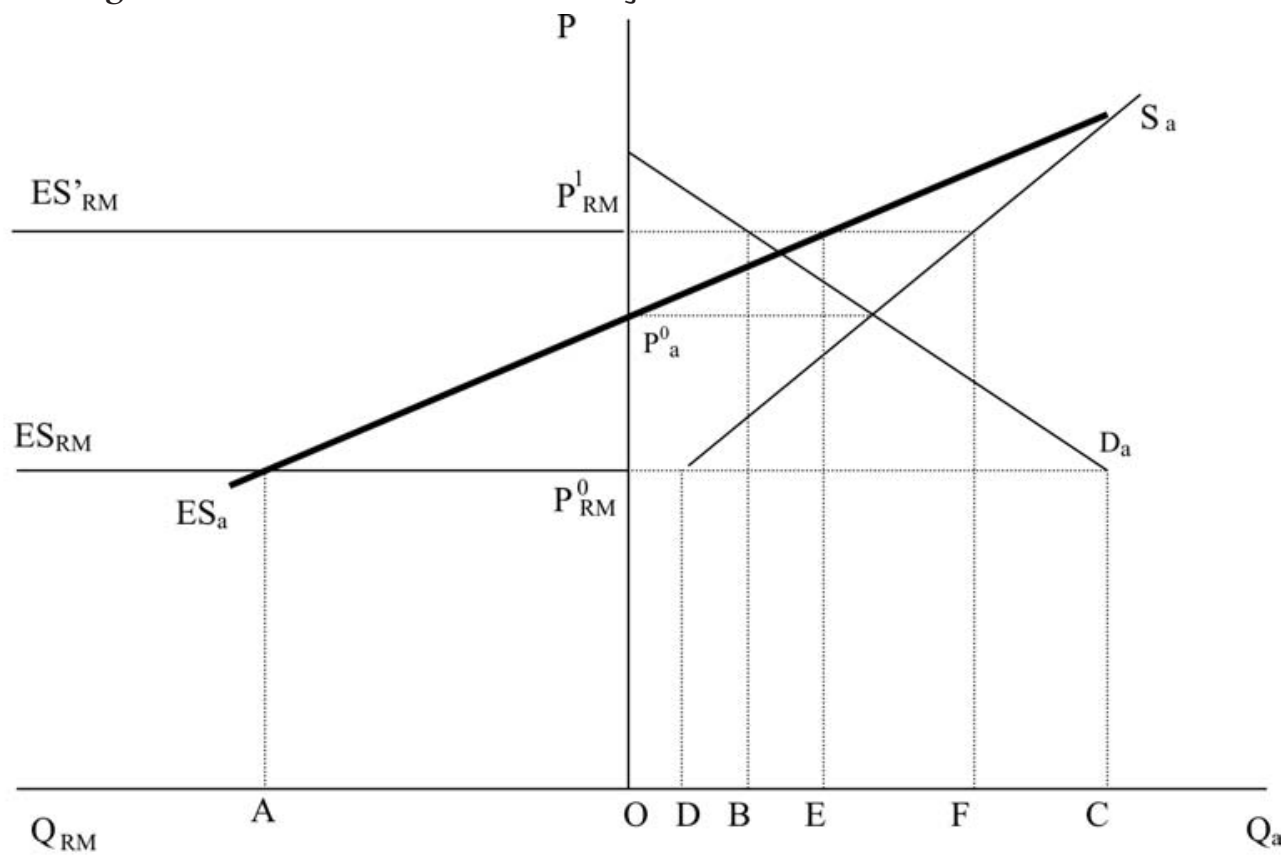

Fonte: Elaboração dos autores.

Especificação da equação de excesso de demanda

As representações gráficas feitas no item anterior admitem um tratamento matemático para melhor definir o modelo a ser estimado no presente estudo. A função de excesso de demanda pode ser definida por:

$$
\begin{aligned}
& M_{t}^{d}=Q^{d}-Q^{s} \\
& M_{t}^{d}=Q^{d}\left(P_{d t}, P_{m t}, E_{t}, Y\right)-Q^{s}\left(P_{d t}, W\right)
\end{aligned}
$$

que numa representação linear será:

$$
\begin{aligned}
& M_{t}^{d}=\left(\alpha_{0}+\alpha_{1} P_{d t}+\alpha_{2} P_{m t}+\alpha_{3} E_{t}+\alpha_{4} Y\right)-\left(\beta_{0}+\beta_{1} P_{d t}+\beta_{2} W\right) \\
& M_{t}^{d}=\left(\alpha_{0}-\beta_{0}\right)+\left(\alpha_{1}-\beta_{1}\right) P_{d t}+\alpha_{2} P_{m t}+\alpha_{3} E_{t}+\alpha_{4} Y-\beta_{2} W
\end{aligned}
$$

Em que:

$M_{t}^{d}=$ função de excesso de demanda por leite importado;

$Q^{d}=$ função de demanda por leite importado;

$Q^{s}=$ função de oferta de leite;

$P_{d t}=$ preço do leite no mercado doméstico;

$P_{m t}=$ preço do leite no mercado externo;

$E_{t}=$ taxa de câmbio;

$Y=$ variáveis deslocadoras da demanda (renda interna, gosto e preferência); 
$W=$ variáveis deslocadoras da oferta (safra, entressafra, melhoria genética);

$\alpha_{0}, \alpha_{1}, \alpha_{2}, \alpha_{3}, \alpha_{4}, \beta_{0}, \beta_{1}, \beta_{2}=$ coeficientes associados às variáveis explicativas.

Vale salientar que a inclusão do preço doméstico ao lado do preço do produto importado pressupõe que o produto não seja substituto perfeito do ponto de vista da indústria processadora ou dos consumidores nacionais.

Pode-se ainda, como forma de adequar o modelo proposto na equação (1) com os objetivos do trabalho, adicionar algumas variáveis qualitativas do tipo dummy. O objetivo é admitir que existam outras variáveis importantes na especificação da demanda por leite importado que não foram incorporadas na equação (1), como, por exemplo, o efeito da estabilização monetária com o advento do Plano Real em julho de 1994 e o efeito das medidas anti-dumping que o governo implementou a partir de 2001. Assim:

$M_{t}^{d}=\left(\alpha_{0}-\beta_{0}\right)+\left(\alpha_{1}-\beta_{1}\right) P_{d t}+\alpha_{2} P_{m t}+\alpha_{3} E_{t}+\alpha_{4} Y-\beta_{2} W+\gamma_{1} D_{1}+\gamma_{2} D_{2}$

em que: $D_{1}=$ dummy para a estabilização monetária; $D_{2}=$ dummy para as medidas anti-dumping; $\gamma_{1}, \gamma_{2}=$ coeficientes associados às variáveis dummies.

Será feito o teste de causalidade de Granger para calcular a relação entre $M_{t}^{d}$ e $P_{m t}$. Vale lembrar que a formulação gráfica e algébrica adotada necessita da hipótese de que $P_{m t}$ seja exógena em relação à $M_{t}^{d^{s}}$. Ou seja, $M_{t}^{d}$ não afeta $P_{m t}$ contemporaneamente (por pressuposição) ou com defasagens. Caso esta relação se mostre bicausal, não se sustenta a exogeneidade em vista de efeito defasado de $M_{t}^{d}$ sobre $P_{m t}$. Deve-se abrir, então, a possibilidade de ocorrer também efeito contemporâneo entre essas variáveis. Segundo Barros (2003), há, portanto, que se substituir a linha horizontal de $\mathrm{ES}_{\mathrm{RM}}$ por uma linha negativamente inclinada: maiores preços aumentam o excesso de oferta (medido da direita para a esquerda) mundial para o Brasil. Essa linha pode ser representada com $P_{m t}$ como variável dependente e $M_{t}^{d}$ como variável explicativa.

$$
P_{m t}=\lambda_{0}+\lambda_{1} M_{t}^{s}+\lambda_{2} L_{t}^{w}+v_{t}
$$

Em que $M_{t}^{s}=$ oferta do resto do mundo para o Brasil, $L_{t}^{w}=$ total de exportações mundiais de leite e $\lambda_{1}>0$ e $\lambda_{2}<0$. Quanto maior o preço de importação leite $\left(P_{m t}\right)$ maior será a oferta de leite para o Brasil $\left(M_{t}^{s}\right)$. Quanto maior $P_{m t}$, menor o total das exportações mundiais de leite $\left(L_{t}^{w}\right.$ ). O modelo se equilibra quando $M_{t}^{d}=M_{t}^{s}=M$

Conforme Gujarati (1995), caso exista simultaneidade, os métodos de Mínimos Quadrados de Dois Estágios (MQ2E) e de variáveis instrumentais serão os indicados, pois seus estimadores serão consistentes e eficientes.

Para se testar a exogeneidade fraca utilizar-se-á o teste de Hausman. (Gujarati,1995). Ou seja, verificar-se-á se o resíduo da equação (2) é significativo pelo teste $t$ de Student na equação (3), a seguir apresentada. Da mesma forma, se o resíduo da equação (3) for significativo pelo teste $t$ na equação (2), existirá causalidade fraca, condição suficiente para que exista causalidade entre a variável $M_{t}^{d}$ e $P_{m t}$. (Greene, 2000; Judge et alii, 1985). 


\subsection{Modelo empírico}

Para analisar empiricamente os determinantes das importações de leite pelo Brasil foi estimada a função de demanda por leite importado. A equação genérica de importação de leite para o Brasil é apresentada pela equação (3):

$$
\begin{aligned}
& M_{t}^{d}=\left(\alpha_{0}-\beta_{0}\right)+\left(\alpha_{1}-\beta_{1}\right) P_{d t}+\alpha_{2} P_{m t}+\alpha_{3} E_{t}+\alpha_{4} Y_{t}+\gamma_{1} D_{1}+\gamma_{2} D_{2}+\varepsilon_{t} \\
& M_{t}^{d}=\theta_{0}+\theta_{1} P_{d t}+\alpha_{2} P_{m t}+\alpha_{3} E_{t}+\alpha_{4} Y_{t}+\gamma_{1} D_{1}+\gamma_{2} D_{2}+\varepsilon_{t}
\end{aligned}
$$

em que: $M_{t}^{d}=$ quantidades mensais de importação de lácteos no período de 1991 a 2003; $\theta_{0}=$ coeficiente autônomo; $\theta_{1}, \alpha_{2}, \alpha_{3}, \alpha_{4}, \beta_{1}, \gamma_{1}, \gamma_{2}=$ coeficientes associados às variáveis explicativas; $P_{d t}$ $=$ preços mensais de leite em $\mathrm{R} \$ / 1000$ litros no período de 1991 a 2003; $P_{m t}=$ preços mensais de importação de lácteos em US $\$ / 1000$ litros no período de 1991 a 2003; $E_{t}=$ taxa mensal de câmbio real no período de 1991 a 2003; $Y_{t}=$ produto interno mensal per capita deflacionado pelo IGP-DI (FGV) no período de 1991 a 2003; $D_{1}=$ estabilização monetária no mês de julho de 1994 (0 até junho de 1994 e 1 nos demais meses de 1994); $D_{2}=$ medidas anti-dumping a partir de fevereiro de 2001 ( 0 até janeiro de 2000 e 1 nos demais meses); $\varepsilon_{t}=$ erro aleatório no período analisado.

Os sinais esperados para os parâmetros da equação (3) são $\theta_{0}>0, \theta_{1}>0, \alpha_{2}<0, \alpha_{3}<0$, $\alpha_{4}>0, \gamma_{1}<0, \gamma_{2}>0$. A literatura consultada em vários trabalhos sobre estimação da equação de demanda de importação sugere que se aplique na equação (3) o modelo duplo-logaritmo. Procurar-se-á determinar, por meio do teste de sentido de causalidade de Granger, se a quantidade importada de leite $\left(M_{t}^{d}\right)$ é causada pelo preço de importação $\left(P_{m t}\right)$, e vice-versa, ou em ambos os sentidos, bem como determinar, por meio do teste de Hausman, se a exogeneidade é fraca. Além disso, proceder-se-á a uma série de testes econométricos como de raiz unitária e o de co-integração de Johansen. (Ver mais detalhes em Guajarati, 1995 e Bacchi, 2001).

\section{Resultados}

Os testes de raiz unitária para as séries foram realizados em termos logarítmicos: importação mensal de leite $\left(l M_{t}^{d}\right)$, preço mensal de leite no mercado interno $\left(l P_{d t}\right)$, preço mensal de importação de leite $\left(l P_{m t}\right)$, taxa mensal de câmbio real $\left(l E_{t}\right)$, PIB mensal per capita $\left(l Y_{t}\right)$ e exportação mensal mundial de leite $\left(l L^{w}\right)$. Utilizou-se o procedimento proposto por Enders (2004) para identificar o modelo específico a ser considerado no teste, incluindo ou não termos deterministas.

As variáveis relacionadas pelo modelo apresentaram, no teste de raiz unitária, ordem de integração igual a 1, [I(1)]. Isto significa que elas não rejeitam a hipótese nula de raiz unitária, sendo necessário que na especificação do modelo elas sejam consideradas nas diferenças de primeira ordem. Ou seja, a estacionariedade das séries só foi configurada nas diferenças quando os valores encontrados foram superiores ao valor crítico ao nível de $1 \%$ (Tabela 5).

Para todas as variáveis foram encontrados níveis de significância da estatística Q do teste de Ljung-Box maiores que 0,48, rejeitando a hipótese nula desse teste, que considera a existência de autocorrelação serial entre os resíduos. 
Tabela 5 - Teste de raiz unitária em modelo sem constante e sem tendência, estatística $\tau^{1}$

\begin{tabular}{lccc}
\hline$\Delta \Delta x_{t}=\sigma_{1} \Delta x_{t-1}+\sum_{j=1}^{n} \sigma_{j} \Delta \Delta x_{t-j}+\varepsilon_{t}$ & $\mathrm{H} 0: \sigma_{1}=0$ & \\
\hline Variáveis & Valor de $p-1$ & $\begin{array}{c}\text { Valor da estatística t } \\
\mathrm{H}_{0}: \sigma_{1}=0\end{array}$ & Nível de significância da estatística "Q" \\
\hline$\Delta l M_{t}^{d}$ & 12 & $-3,69^{*}$ & 0,99 \\
$\Delta l P_{d t}$ & 6 & $-7,29^{*}$ & 0,62 \\
$\Delta l P_{m t}$ & 8 & $-4,86^{*}$ & 0,48 \\
$\Delta l E_{t}(2)$ & 1 & $-5,20^{*}$ & 0,89 \\
$\Delta l Y_{t}$ & 12 & $-3,35^{*}$ & 0,49 \\
$\Delta l L_{t}^{w}$ & 12 & $-3,18^{*}$ & 0,80 \\
\hline
\end{tabular}

Fonte: Dados da pesquisa.

(1) Valores críticos de $\tau$ conforme descrito por Dickey e Fuller (1981) e corresponde a -1,95 em nível de 5\% e -2,60 em nível de $1 \%$.

(2) Ajustado com duas quebras estruturais (janeiro de 1999 e maio de 2002).

Significativo ao nível de significância de $1 \%$.

Os testes de co-integração foram realizados entre as variáveis duas a duas, para obter os termos de correção de erro para os testes de causalidade. Os resultados estão apresentados na Tabela 6. O valor do teste "t" para o resíduo $(-3,83)$ no teste de co-integração é maior, em módulo, que o valor crítico (vc) de $-3,55$ ao nível de significância de $10 \%$. Conclui-se que há um vetor de co-integração entre as variáveis da equação (i). Considerando a equação (ii), o valor do teste $t$ para o resíduo $(-3,85)$ no teste de co-integração é significativo ao nível de $10 \%$. Conclui-se, pois, que na equação (ii) existe um vetor de co-integração.

\section{Tabela 6 - Resultados do teste de co-integração}

\begin{tabular}{|c|c|}
\hline Regressão estimada para testar a co-integração & Resultado do teste de estacionariedade aplicado no resíduo estimado \\
\hline \multirow{3}{*}{$\begin{array}{c}\text { (i) } l M_{t}^{d}=8,007548-0,5634245 l P_{m t} \\
\mathrm{R}^{2}=0,99\end{array}$} & $\mathrm{t}=-3,83$ \\
\hline & $\mathrm{vc}(5 \%)=-3,89^{*}$ \\
\hline & $\mathrm{vc}(10 \%)=-3,55^{*}$ \\
\hline \multirow{3}{*}{ 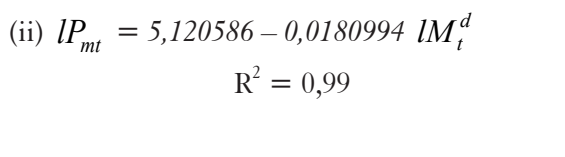 } & $\mathrm{t}=-3,85$ \\
\hline & $\mathrm{vc}(5 \%)=-3,89^{*}$ \\
\hline & $\mathrm{vc}(10 \%)=-3,55^{*}$ \\
\hline
\end{tabular}

* valor crítico para 100 observações e 1 variável (Harris, 1995).

Os resultados das equações definidas no teste de causalidade ${ }^{4}$ são apresentados na Tabela 7. As relações de causalidade fornecem uma indicação mais precisa das relações comportamentais do mercado importador de leite no País.

4 As defasagens do teste de causalidade foram obtidas pelo critério de Akaike e Schwartz. 
Observa-se um sentido bicausal no mercado importador de leite, em que a quantidade importada de leite $\left(\Delta l M_{t}^{d}\right)$ causa o preço de importação de leite $\left(\Delta l P_{m t}\right)$ e, simultaneamente, o preço de importação de leite $\left(\Delta l P_{m t}\right)$ causa a quantidade de leite importado $\left(\Delta l M_{t}^{d}\right)$. Portanto, será estimado o modelo pelo método de Mínimos Quadrados de Dois Estágios (MQ2E), uma vez que existe uma relação endógena no sistema de equações. Além disso, as equações (2) e (3) são sobreidentificadas, indicando a utilização do método de MQ2E.

Tabela 7 - Resultados do teste de causalidade de Granger com termo de correção de erro

\begin{tabular}{ccccc}
\hline Variável dependente & Variável explicativa & $p$ Teste $\mathrm{F}$ & $p$ Teste t & Teste $\mathrm{Q}$ \\
\hline$\Delta l M_{t}^{d}$ & $\Delta l P_{m t}$ & 0,001 & 0,003 & 0,16 \\
$\Delta l P_{m t}$ & $\Delta l M_{t}^{d}$ & 0,001 & 0,002 & 0,18 \\
\hline
\end{tabular}

Fonte: Dados de pesquisa.

Conclui-se que há exogeneidade fraca, pois os resíduos são significativos pelo teste $t$. Assim, pode-se afirmar que existe causalidade entre $\Delta l M_{t}^{d}$ e $\Delta l P_{m t}$, sendo condição necessária à exogeneidade forte. A fraca, referendada pelo teste de Hausman, é condição suficiente para confirmar a causalidade no sentido de Granger, uma vez que o objetivo é a estimação de variáveis endógenas (Ver Tabela 8).

Tabela 8 - Resultados do teste de Hausman

\begin{tabular}{|c|c|c|c|c|}
\hline \multirow{2}{*}{ Variáveis } & \multicolumn{2}{|c|}{$\Delta l M_{t}^{d}$} & \multicolumn{2}{|c|}{$\Delta l P_{m t}$} \\
\hline & Coeficiente & Valor $p$ de $t$ & Coeficiente & Valor $p$ de $t$ \\
\hline Constante & 9,045811 & 14,96971 & 4,342549 & 24,73361 \\
\hline$\Delta l M_{t}^{d}$ & - & - & $-0,652837$ & $-40,32745$ \\
\hline$\Delta l P_{d t}^{(1)}$ & 2,488259 & 7,84625 & - & - \\
\hline$\Delta l P_{m t}$ & $-6,350305$ & $-31,97191$ & - & - \\
\hline$\Delta l E_{t}(1,2)$ & $-1,358041$ & $-5,70965$ & $-0,858267$ & $-13,43305$ \\
\hline$\Delta l Y_{t}^{(1)}$ & 6,410267 & 9,46624 & 1,823598 & 11,91541 \\
\hline$\Delta l L_{t}^{w}(1)$ & 1,328282 & 3,40598 & $-0,611759$ & $-7,17624$ \\
\hline$\hat{l}_{t}$ & $6,331356^{*}$ & 27,72871 & - & - \\
\hline$\hat{\varpi}_{t}$ & - & - & $0,652837^{*}$ & 35,75900 \\
\hline$r 1^{(1)}$ & $-0,024938$ & $-15,31705$ & $-0,006616$ & $-18,19791$ \\
\hline$r 2^{(1)}$ & $-0,184431$ & $-14,06500$ & $-0,093189$ & $-24,29216$ \\
\hline $\mathrm{D}_{1}$ & $-0,195657$ & $-5,28205$ & 0,001113 & 0,12177 \\
\hline \multirow[t]{2}{*}{$\mathrm{D}_{2}$} & $-0,004756$ & $-0,20205$ & 0,054068 & 8,88968 \\
\hline & \multicolumn{2}{|c|}{$F=56,12^{*}$} & \multicolumn{2}{|c|}{$F=89,47^{*}$} \\
\hline
\end{tabular}

Fonte: Dados da pesquisa.

* Significativo ao nível de significância de $1 \%$.

${ }^{(1)}$ Variável defasada; ${ }^{(1,2)}$ Variável defasada com duas quebras estruturais. 
Nos resultados da análise de co-integração para as séries de mesma ordem, os testes do máximo autovalor e do traço indicam que há dois vetores de co-integração (Tabela 9). Assim sendo, os resultados mostram que existem relações de equilíbrio de longo prazo entre as variáveis.

Tabela 9 - Resultados do teste de co-integração de Johansen

\begin{tabular}{cccc}
\hline Hipótese Nula & Hipótese Alternativa & $\lambda_{\max }$ & $\lambda_{\text {trace }}$ \\
\hline$r \leq 5$ & $r=6$ & 3,628 & 3,628 \\
$r \leq 4$ & $r=5$ & 10,814 & 14,441 \\
$r \leq 3$ & $r=4$ & 15,053 & 29,494 \\
$r \leq 2$ & $r=3$ & 26,845 & 56,339 \\
$r \leq 1$ & $r=2$ & $44,088^{*}$ & $100,427^{*}$ \\
$r \leq 0$ & $r=1$ & $86,955^{*}$ & $187,382^{*}$ \\
\hline
\end{tabular}

Fonte: Dados da pesquisa.

* Significativo a 1\% de significância [valores críticos em Osterwald-Lenum (1992)].

\section{Estimação das funções de demanda e preço de leite importado}

$\mathrm{Na}$ estimação das referidas equações (Tabela 10), todas as variáveis apresentaram sinais coerentes com a teoria econômica e nível de significância a pelo menos $10 \%$, à exceção das variáveis dummies que indicavam estabilidade econômica (D1) e política anti-dumping (D2) relacionada na equação de demanda por leite importado $\left(\Delta l M_{t}^{d}\right)$. As variáveis relacionadas pela pesquisa do comportamento da demanda por leite importado explicaram $34 \%$ das importações de leite, conforme sugere o coeficiente de determinação.

Tabela 10 - Estimativas do ajustamento em dois estágios da demanda por leite importado $\left(M_{t}^{d}\right)$ e do preço de importação $\left(P_{m t}\right)$

\begin{tabular}{|c|c|c|}
\hline \multirow{2}{*}{ Variáveis } & $\Delta l M_{t}^{d}$ & $\Delta l P_{m t}$ \\
\hline & \multicolumn{2}{|c|}{ Coeficientes } \\
\hline Constante & $6,185614^{* *}$ & $0,645634^{* *}$ \\
\hline$\Delta l P_{m t}^{(1)}$ & $-1,562731^{* *}$ & - \\
\hline$\Delta l M_{t}^{d}$ & - & $-0,124643^{* *}$ \\
\hline$\Delta l L_{t}^{w^{(1)}}$ & - & $-0,439108^{*}$ \\
\hline$\Delta l E_{t}^{(1,2)}$ & $-1,183131^{* \star}$ & - \\
\hline$\Delta l Y_{t}^{(1)}$ & $2,982639^{* *}$ & - \\
\hline$\Delta l P_{d t}^{(1)}$ & $1,643824^{*}$ & - \\
\hline$r 1^{(1)}$ & $-0,009389^{* *}$ & $-0,002861^{* *}$ \\
\hline$r 2^{(1)}$ & $-0,132842^{\star *}$ & $-0,012235^{\star *}$ \\
\hline$D 1$ & 0,001714 & - \\
\hline$D 2$ & 0,074887 & - \\
\hline$R^{2}$ & 0,3432 & 0,2224 \\
\hline
\end{tabular}

Fonte: Dados de pesquisa.

* Significativo a $1 \%, *$ Significativo a $10 \%$.

${ }^{(1)}$ Variável defasada;

${ }^{(1,2)}$ Variável defasada e com duas quebras estruturais. 
As variáveis relacionadas para a estimação da equação de preço de leite importado $\left(\Delta l P_{m t}\right)$ apresentaram sinal coerente com a teoria econômica. As variáveis quantidade demandada de leite pelo País e produção mundial de leite explicaram $22 \%$ dos preços de importação pagos pelo Brasil ,como sugere o coeficiente de determinação.

Para interpretar os resultados, tomou-se como ilustração o efeito do crescimento da economia brasileira. Um aumento no PIB brasileiro tende a aumentar o volume importado que, por sua vez, eleva o preço de importação, contendo parcialmente o efeito de crescimento das importações. Da mesma forma, uma expansão da produção mundial reduz o preço de importação, que provoca um aumento nas importações, que atenua a queda original de preço.

Tratando-se de um sistema de duas equações simultâneas, a interpretação dos efeitos de choques nas variáveis exógenas sobre as endógenas $\left(\Delta l M_{t}^{d} e \Delta l P_{m t}\right)$ ficou facilitada a partir de sua forma reduzida. Esta pode ser obtida resolvendo-se o sistema para as variáveis endógenas relativamente a todas as exógenas, como, por exemplo, substituir $\Delta l M_{t}^{d}$ na equação de $\Delta l P_{m t}$; o resultado foi, então, substituído em $\Delta l M_{t}^{d}$. Os dados encontram-se na Tabela 11.

$\mathrm{Na}$ equação da demanda por leite importado, as variáveis-preço de importação de leite, taxa de câmbio real, PIB per capita real e preço interno de leite apresentaram coeficientes significativos e sinais coerentes com a teoria econômica. As elasticidades estimadas foram todas próximas ou superiores à unidade, revelando um mercado bastante dinâmico com ajustes rápidos no curto prazo. A demanda por importação mostrou-se bastante elástica tanto em relação ao preço de importação como ao preço doméstico. As elasticidades foram de magnitudes bem parecidas - mas, evidentemente, de sinais opostos -, sugerindo uma boa integração do segmento leiteiro ao mercado internacional: variações iguais nos dois preços, mantida a taxa de câmbio, pouco alterariam o volume importado de leite. O crescimento da renda tendeu a resultar em incremento importante das importações, indicando que o setor nacional tem dificuldade de atender a um crescimento mais rápido do consumo interno. $\mathrm{O}$ câmbio real foi um fator relevante para as importações de lácteos na medida em que é determinante do preço relativo dos produtos nacional e importado.

Tabela 11 - Resultados para a forma reduzida do sistema

\begin{tabular}{lcc}
\hline & $\Delta l M_{t}^{d}$ & $\Delta l P_{m t}$ \\
\cline { 2 - 3 } Variáveis & \multicolumn{2}{c}{ Coeficientes } \\
\hline Constante & 6,429 & $-0,158$ \\
$\Delta l E_{t}$ & $-1,469$ & 0,184 \\
$\Delta l Y_{t}$ & 3,706 & $-0,463$ \\
$\Delta l P_{d t}$ & 2,042 & $-0,255$ \\
$\Delta l L_{t}^{w}$ & $-0,852$ & 0,546 \\
$r 1$ & $-0,005$ & 0,001 \\
$r 2$ & $-0,068$ & 0,021 \\
$D 1$ & 0,002 & 0,003 \\
$D 2$ & 0,093 & $-0,012$ \\
\hline
\end{tabular}

Fonte: Dados de pesquisa.

No tocante à oferta de leite importado, nota-se que o preço pago pelo Brasil é negativamente influenciado pela oferta internacional. As importações brasileiras influenciam o preço pago em 
moeda estrangeira, mas o sinal negativo obtido contraria as expectativas teóricas, embora não seja impossível que tal sinal ocorra na prática, ou seja, que o preço pago caia com o volume de compras, como é comum em práticas comerciais. É importante também reconhecer que as dummies incluídas para captar as variações de políticas econômicas, como a estabilização monetária e as políticas anti-dumping, não apresentaram efeitos significativos. Como se supunha, é possível que seus efeitos tenham sido captados por outras variáveis presentes no modelo, como preços e câmbio.

\section{CONCLUSÕES}

O mercado de leite passou por substanciais mudanças institucionais, estruturais e tecnológicas na última década. Assim mesmo, apresentou um dinamismo importante ao suportar longo período de intensa concorrência externa a preços artificialmente baixos. Os ajustes promovidos em resposta aos desafios permitiram reduções de preços domésticos, avanços na qualidade do produto e uma reversão nas tendências de comércio exterior, caminhando agora para resultados superavitários.

Com relação à forma e ao grau de inserção internacional que influenciou o mercado interno, percebeu-se que a importação de leite foi importante, durante o período analisado, como complementação da produção doméstica, e espera-se que continue tendo papel relevante, mesmo porque o intercâmbio comercial intra-indústria apresenta peculiaridades que tornam eficiente a exportação de certos derivados e importação de outros.

As importações brasileiras mostraram-se influenciadas por preços internacionais e domésticos, indicando não serem os produtos importados e produzidos internamente perfeitamente substituíveis. Por outro lado, notou-se que o setor lácteo por si só acha-se bem integrado ao mercado externo, de sorte a ter neste mercado a referência norteadora: os preços de importação oferecendo um teto para o mercado doméstico, e os preços de exportação, um piso, não necessitando de medidas adotadas pelo governo brasileiro.

Além disso, os valores relativamente altos das elasticidades da função de importação sugerem um dinamismo do setor no tocante a ajustamentos no suprimento diante de oscilações de preço e câmbio. O crescimento da renda tendeu a resultar em incremento importante das importações, indicando que o setor nacional tem dificuldade de atender a um crescimento mais rápido do consumo interno.

\section{REFERÊNCIAS BIBLIOGRÁFICAS}

Bacchi, M. R. P. Integração, co-integração e modelo de correção de erro: uma introdução. Piracicaba: EsalqUSP, 2001. Mimeografado.

Barros, G. S. C. Economia da comercialização. Centro de Estudos Avançados em Economia Aplicada. ESALQ/USP, 1987, 360 p. Disponível em: http://www.cepea.esalq.usp.br. Acesso em março de 2003.

Barros, G. S. C.; Galan, V. B.; Guimarães, V. A.; Bacchi, M. R. P. Sistema agroindustrial do leite no Brasil. Brasília: Embrapa Informação Tecnológica, 2001. 170p.

Brandão, A. S. P; Leite, J. L. B. Características principais do comércio internacional de leite. In: Gomes, A. T.; Leite, J. L. B.; Carneiro, A. V. (eds.), O agronegócio do leite no Brasil. Juiz de Fora: Embrapa Gado de Leite, 2001. p. 167-180.

Dickey, D.A.; Fuller, W. A. Likelihood ratio statistics for auto-regressive time series with a unit root. Econometrica, v. 49, n. 4, p. 1057-1072, 1981. 
FAO - Food and Agriculture Organization. Disponível em: http://www.fao.org. Acesso em: maio de 2003.

Greenshields, B. F. Changes in exchange rates: impact on US grain and soybean exports to Japan. FAER, 364. Economic Research Service, Washington: US Department of Agriculture, July 1974.

Gujarati, D. N. Basic econometrics. Singapore: McGraw-Hill International Editions, 1995.

HARRIS, R. Using cointegration analysis in econometric modelling. UK: Prentice Hall-Harvest Wheatsheaf, 1995.

Judge, G. G.; Griffiths, W. E.; Hill, R. C.; Lütkepohl, H.; Lee, T. C. The theory and practice of econometrics. New York: John Wiley and Sons, 1985.

Martins, P. C. Políticas públicas e mercados deprimem o resultado do sistema agroindustrial do leite. Piracicaba, 2002. 217p. Tese (Doutorado) - Escola Superior de Agricultura "Luiz de Queiroz" - USP.

OCDE - Organização de Cooperação e Desenvolvimento Econômico. Disponível Em: http://www.oecd. org. Acesso em: setembro de 2004.

Orden, D. A critique of exchange rate treatment in agricultural trade models: comment. American Journal of Agricultural Economics, v. 68, 1986.

Osterwald-Lenum, M. A note with quanlites of the asymptotic distribution of the maximum likehood cointegration rank test statistics. Oxford Bulletion of Economics and Statistics, v. 54, n. 3, 1992.

Portugal, L. Methodology for the measurement of support and use in policy evaluation. OECD. Disponível em: http://www.oecd.org. Acesso em: setembro de 2004.

Thorstensen, V. OMC - Organização Mundial do Comércio: as regras do comércio internacional e a rodada do milênio. São Paulo: Aduaneiras, 1999. 406p.

USDA - Departamento de Agricultura dos Estados Unidos da América. Disponível em: http://www.usda. gov/wps/portal/usdahome. Acesso em outubro de 2004. 